Article

\title{
Essential Amino Acid Supplement Lowers Intrahepatic Lipid despite Excess Alcohol Consumption
}

\author{
Melynda S. Coker ${ }^{1}\left(\mathbb{D}\right.$, Kaylee R. Ladd ${ }^{2}$, Jimin Kim ${ }^{2}{ }^{(0}$, Carl J. Murphy ${ }^{3}$, Ryan DeCort ${ }^{4}$, \\ Bradley R. Newcomer ${ }^{5}$ (D), Robert R. Wolfe ${ }^{6}$ and Robert H. Coker ${ }^{2,3, *(D)}$ \\ 1 Department of Natural Resources and Environment, University of Alaska Fairbanks, 505 South Chandalar \\ Drive, Fairbanks, AK 99775, USA; mscoker@alaska.edu \\ 2 Department of Biology and Wildlife, University of Alaska Fairbanks, Fairbanks, AK 99775, USA; \\ krladd@alaska.edu (K.R.L.); jkim96@alaska.edu (J.K.) \\ 3 Institute of Arctic Biology, Department of Chemistry \& Biochemistry, University of Alaska Fairbanks1930 \\ Yukon Dr. Room 136, Fairbanks, AK 99775, USA; cjmurphy4@alaska.edu \\ 4 Bassett Army Community Hospital, 4076 Neely Road, Fort Wainwright, United States Army, Fairbanks, \\ AK 99703, USA; rdecort@gmail.com \\ 5 Honors College, 1501251 Warren Service Drive, Room 105, James Madison University, Harrisonburg, \\ VA 22807, USA; newcombr@jmu.edu \\ 6 Department of Geriatrics, Center for Translational Research in Aging \& Longevity, Donald W. Reynolds \\ Institute on Aging, 4301 West Markham, University of Arkansas for Medical Sciences, Little Rock, AR 72205, \\ USA; rwolfe2@uams.edu \\ * Correspondence: rcoker@alaska.edu; Tel.: +1-907-474-7640; Fax: +1-907-474-7666
}

Received: 16 December 2019; Accepted: 9 January 2020; Published: 19 January 2020

check for updates

\begin{abstract}
Excess alcohol consumption is a top risk factor for death and disability. Fatty liver will likely develop and the risk of liver disease increases. We have previously demonstrated that an essential amino acid supplement (EAAS) improved protein synthesis and reduced intrahepatic lipid in the elderly. The purpose of this exploratory pilot study was to initiate the evaluation of EAAS on intrahepatic lipid (IHL), body composition, and blood lipids in individuals with mild to moderate alcohol use disorder (AUD). Following consent, determination of eligibility, and medical screening, 25 participants (18 males at $38 \pm 15$ years/age and 7 females at $34 \pm 18$ years/age) were enrolled and randomly assigned to one of two dosages: a low dose (LD: $8 \mathrm{~g}$ of EAAS twice/day (BID)) or high dose (HD: $13 \mathrm{~g}$ of EAAS BID). Five of the twenty-five enrolled participants dropped out of the intervention. Both groups consumed the supplement BID for 4 weeks. Pre- and post-EAAS administration, IHL was determined using magnetic resonance imaging/spectroscopy, body composition was analyzed using dual-energy X-ray absorptiometry, and blood parameters were measured by LabCorp. T-tests were used for statistical analysis and considered significant at $p<0.05$. While there was no significant change in IHL in the LD group, there was a significant $23 \%$ reduction in IHL in the HD group $(p=0.02)$. Fat mass, lean tissue mass, bone mineral content, and blood lipids were not altered. Post-EAAS phosphatidylethanol was elevated and remained unchanged in LD at $407 \pm 141 \mathrm{ng} / \mathrm{mL}$ and HD at $429 \pm 196 \mathrm{ng} / \mathrm{mL}$, indicating chronic and excess alcohol consumption. The HD of the proprietary EAAS formulation consumed BID seemed to lower IHL in individuals with mild to moderate AUD. We suggest that further studies in a larger cohort be conducted to more completely address this important area of investigation.
\end{abstract}

Keywords: amino acids; liver; alcohol 


\section{Introduction}

Alcohol use disorder (AUD) is a leading risk factor for death and disability and is responsible for 69 million disability-adjusted life years (DALYs) [1]. Chronic alcohol use induces hepatic steatosis in $90 \%-95 \%$ of individuals; liver pathology advances to cirrhosis in approximately $8 \%-20 \%$ of individuals with AUD and represents one of the most important clinical problems associated with AUD [2]. Ameliorating the metabolic consequences of AUD requires more than abstinence and good overall nutrition, as the majority of individuals with AUD continue to drink alcohol, increasing their risk for liver disease [3]. This clinical scenario is not dissimilar from other diseases involving lipotoxicity, in which unhealthy human behaviors require a combination of pharmaceutical, surgical, or nutritional approaches [4].

Many individuals with AUD are malnourished, and the degree of alcoholic liver disease severity correlates with the degree of malnutrition [5]. The dietary intake of protein and micronutrients often fails to meet recommended levels, even during professional, supervised recovery from AUD [6,7]. In these circumstances, a nutritional supplement designed to address the specific metabolic issues associated with the condition may provide unique benefits. A variety of nutritional supplements targeting some aspect of the AUD responses are available or have been proposed [8-20]. However, none have corrected the disruptions in macronutrient metabolism that lead to hepatic steatosis [11].

The beneficial influence of unique essential amino acids (EAA) on the stimulation of protein synthesis [12-14] and reduction in hepatic steatosis in older adults without AUD has been demonstrated [13]. Ingestion of $11 \mathrm{~g}$ of an EAA-based formula resulted in a $50 \%$ reduction in liver fat after only four weeks of therapy [13]. Individuals receiving the EAA formula consumed a balanced diet containing at least the minimum RDA for protein [15]. Still, the EAA exerted a profound effect on liver health. The ingestion of an EAA-based formula promotes higher plasma EAA concentrations when compared to isocaloric ingestion of intact protein, corresponding with higher net protein balance [16]. The etiology of hepatic steatosis is not identical among those at risk for metabolic disease and those who present with AUD [17]. Hepatic steatosis can occur in part because of a limitation in mitochondrial function [18], and thus impaired fatty acid oxidative capacity [19]. Impaired fatty acid oxidation results in the channeling of fatty acids into triglyceride synthesis. Based on the importance of EAA in the promotion of mitochondrial protein synthesis in the liver [20], we hypothesized that a nutritional formula enriched with either 8 or $13 \mathrm{~g}$ of EAA (Table 1) would reduce excess intrahepatic lipid in persons with AUD, even when alcohol consumption remained unchanged. If so, the status quo for the treatment of individuals with AUD may be modified to induce improved clinical outcomes in this segment of the population.

Table 1. Essential amino acid supplement (EAAS) formulation.

\begin{tabular}{ccc}
\hline & Low Dose $\mathbf{( 8} \mathbf{g})$ & High Dose (13 g) \\
\hline Essential Amino Acids $(\mathrm{mg})$ & & \\
\hline Leucine & 1483 & 2410 \\
Isoleucine & 732 & 1190 \\
Valine & 954 & 1550 \\
Methionine & 345 & 560 \\
Histidine & 363 & 590 \\
Lysine & 1102 & 1790 \\
Threonine & 548 & 890 \\
Phenylalanine & 911 & 1480 \\
Tryptophan & 148 & 240 \\
\hline Other Ingredients $(\mathrm{mg})$ & & \\
\hline Glutamine & 123 & 200 \\
Carnitine & 308 & 500 \\
Niacinamide & 77 & 125 \\
\hline
\end{tabular}


Table 1. Cont.

\begin{tabular}{ccc}
\hline & Low Dose (8 g) & High Dose (13 g) \\
\hline Ascorbic Acid & 308 & 500 \\
Caffeine & 62 & 100 \\
Sucralose & QS & QS \\
Acesulfame Potassium & QS & QS \\
Citric Acid & QS & QS \\
Malic Acid & QS & QS \\
Sodium Citrate & QS & QS \\
Flavors & QS & QS \\
\hline
\end{tabular}

\section{Materials and Methods}

\subsection{Recruitment}

We utilized newspaper advertisements and posted fliers and employed a secured, telephone answering service, allowing private telephone evaluations of individual eligibility. Once it was established that the individual was a potential participant via telephone screening, we scheduled an actual screening visit at the Clinical Research and Imaging Facility (CRIF), located within the Murie Building on the UAF campus [21]. The location of the CRIF is well suited for work with volunteers from the community as there are dedicated parking spaces, and there is semi-private access with little to no student, faculty, or staff traffic. These were especially important factors in minimizing any stigmas that might be associated with the participation of volunteers in the proposed study. The screening visit included the informed consent process, blood work, and health history. Based on the eligibility criteria for mild to moderate AUD, participants were either eligible to participate or referred to their primary care physician for follow up medical care. The project (Nutrient Formulation for Liver Health: 986801-17) and all related documents were approved on 15 December 2016, by the University of Alaska Fairbanks Institutional Review Board.

We chose to restrict our age range 20-60 years of age, as much older individuals could have promoted significant variability in baseline data due to metabolic changes that occur with aging [22]. When an individual was determined to be potentially eligible via telephone interview, a screening visit was scheduled to perform a medical history and physical exam. All participants were required to have transportation to the site clinic for the screening, consent process, testing sessions, weekly checkups, and pickup/return of the essential amino acid supplement (EAAS). A capability for understanding and providing informed consent was necessary for all participants. After the screening visit, the study physician reviewed the exams and blood sample analysis, and all participants were advised of their health and eligibility status.

\subsection{Exclusion Criteria}

Any person with a pacemaker or other implanted metal, insulin-dependent diabetes, or chronic inflammatory condition were excluded. Individuals taking any type of oral contraceptive or any medication or supplement affecting glucose metabolism were excluded. Individuals with active cancers or malignancies were ineligible, as were those taking corticosteroids by mouth, injection or trans-dermally. If the study physician concluded that any medical condition or current medication represents an unacceptable risk, those individuals were excluded.

\subsection{Study Participants}

Once eligibility was established during a run-in assessment period, participants were randomized to a low dose (LD) (8g of EAAS (twice/day (BID)) or high dose (HD) (13 g of EAAS BID) supplementation and asked to undergo two testing sessions in conjunction with the 4-week supplementation phase. In each of the testing sessions (i.e., pre-supplementation and post-supplementation), participants 
underwent magnetic resonance imaging (MRI)/magnetic resonance spectroscopy (MRS) scans, and dual-energy X-ray absorptiometry (DXA) scans in the CRIF, and blood sampling at LabCorp (Figure 1). During the 4-week supplementation period, participants were requested to visit the CRIF at weekly intervals to retrieve their EAAS, evaluate their compliance with the protocol, and measure their weight. Compliance with the paradigm for EAAS supplementation was performed by the measurement of the weight difference in the EAAS product provided and returned each week.

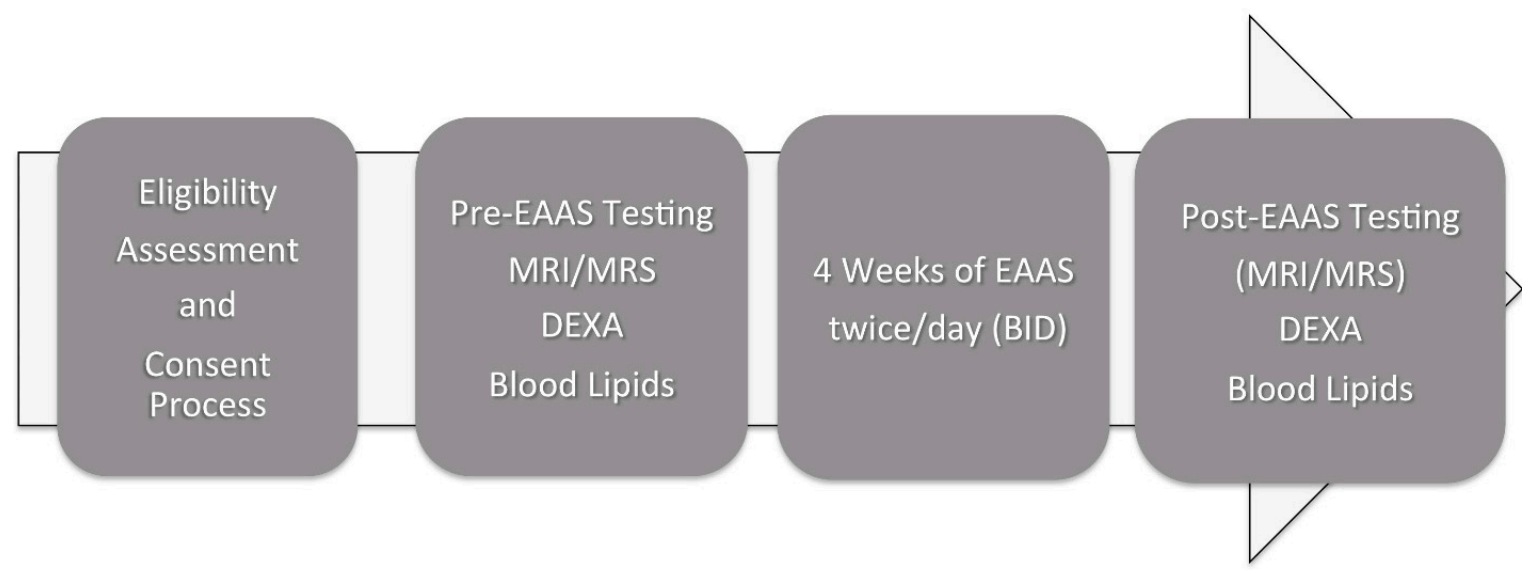

Figure 1. Study timeline.

\subsection{EAAS Formulation}

The proprietary EAAS formulation was produced commercially by the Prinova Group, LLC (Carol Stream, IL, USA) (Table 1). Their regulatory certifications include BRC Global Standards for Food Safety, U.S. Food and Drug Administration Regulated Facility, Kosher Supervision, Non-GMO product, Sedex Approved Supplier, The Islamic Food and Nutrition Council of America, and Safe Feed/Safe Food Certified. In addition to the EAAs, the formula also included glutamine, carnitine, niacinamide, and ascorbic acid that may be deficient in individuals with alcohol use disorder (AUD) (Table 1).

\subsection{Intrahepatic Lipid (IHL)}

We utilized the Toshiba 1.5T Excelart/Vantage with a $1.4 \mathrm{~m}$ magnet and a 65.6 aperture, and IHL measurements were performed in the middle right lobe [23] (Figure 2). The scans were localized to the same area of the liver using the anatomical orientation of the hepatic blood flow and ribs, so that approximately the same area of the liver was scanned during each testing session. After a T1 scan for anatomical structures, a voxel $(\sim 30 \times 30 \times 30 \mathrm{~mm})$ was chosen at a location free from large vessels. An optimized spectroscopy sequence was run 256 times without respiratory gating. These spectra provided an average lipid concentration measurement over the mid-right lobe. Spectra were manually phased, and the final analysis was then performed with jMRUI (Figure 2). 


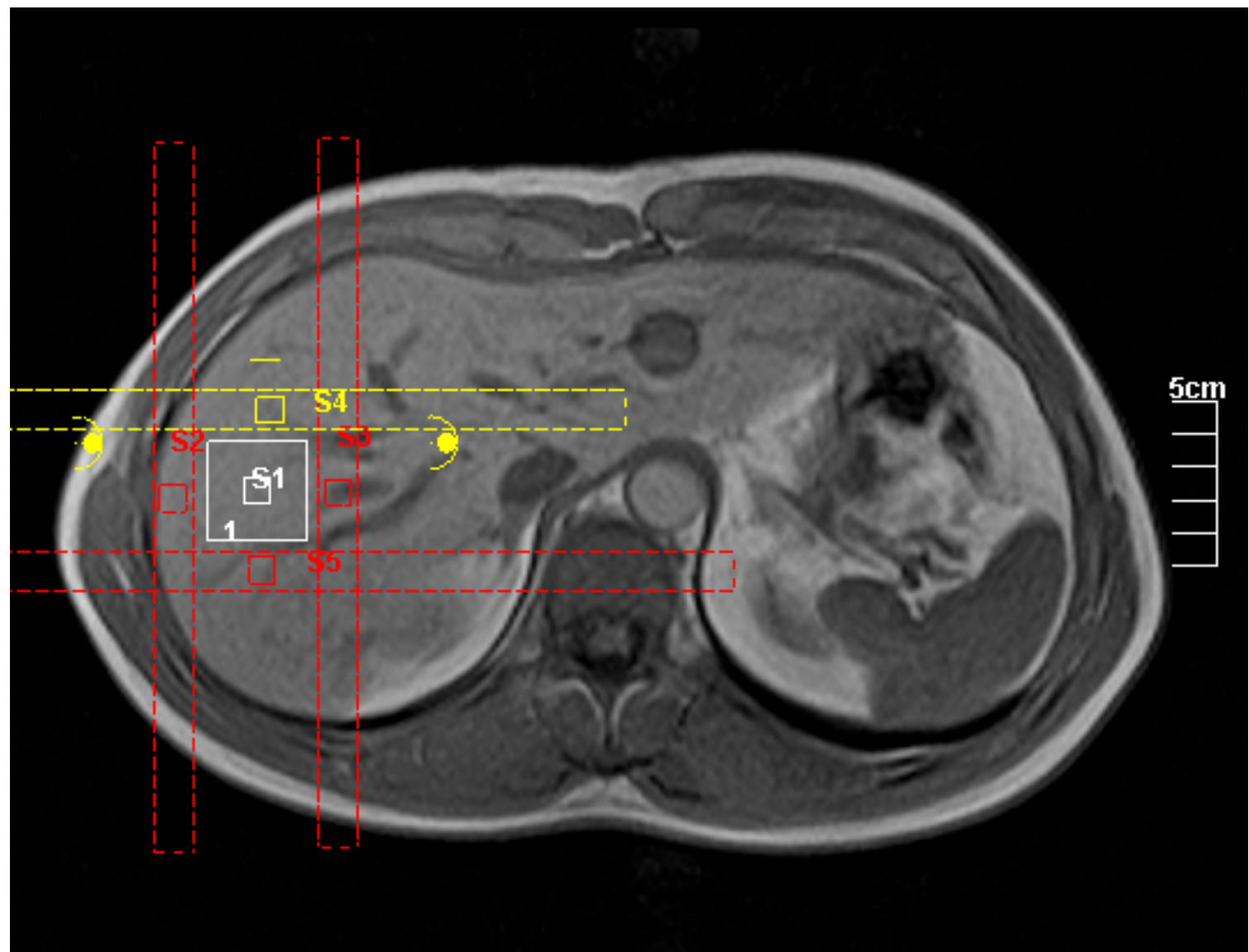

(A)

IHL with water suppressed

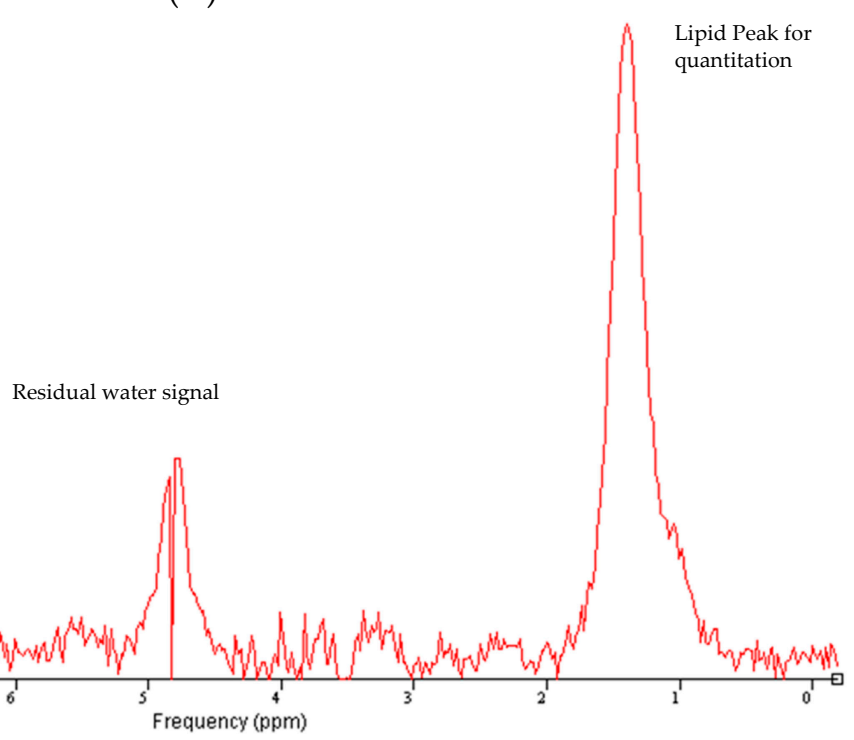

1H-MR spectrum acquired on liver voxel, with solvent suppression

(B)

Figure 2. (A) MRI of liver detailing the location of voxel and (B) an example of 1-H spectroscopy derived measurement of intrahepatic lipid.

\subsection{Body Weight and Composition}

Total body mass was measured using an electronic scale (Health-o-Meter, St. McCook, IL, USA). A General Electric Lunar iDXA was used to determine fat mass, lean tissue mass, and bone mineral content [1]. 


\subsection{Blood Measurements}

Blood sampling and analysis were performed by LabCorp (1626, 30th Avenue, Fairbanks, AK, USA). LabCorp is staffed with licensed healthcare professionals, accredited by the College of American Pathologists, and licensed through the Clinical Laboratory Improvement Amendment (CLIA). In this study, serum lipid, liver, and metabolic panel analysis were included. The lipid panel included total cholesterol, high-density lipoprotein cholesterol (HDL), low-density lipoprotein cholesterol (LDL), very low-density lipoprotein cholesterol (VLDL), and triglycerides. The liver panel consisted of albumin, alanine transaminase (ALT), aspartate transaminase (AST), bilirubin (total and direct), and total protein. The metabolic panel included blood urea nitrogen (BUN), calcium, carbon dioxide, chloride, creatinine, glucose, potassium, and sodium. Whole blood phosphatidylethanol (Peth) was measured to ascertain the level of alcohol consumption.

\subsection{Statistical Analysis}

Data were analyzed using Microsoft Excel, General Electric iDXA Encore, and Prism 5 software. Data are presented as means \pm SD. Two sample homoscedastic $t$-tests were used to evaluate potential differences between groups. In order to generate statistical data for this exploratory pilot study, paired t-tests were utilized to compare differences in pre-supplementation and post-supplementation within groups.

\section{Results}

Research Participants. We enrolled 25 research participants (18 males and 7 females) with mild to moderate AUD for this study. Seventeen individuals completed all aspects of the study; five dropped out and three participants failed to get their post-supplementation blood sampling. Based on EAAS weigh back data, the average daily compliance to EAAS was $85 \% \pm 15 \%$ and $83 \% \pm 8 \%$ in LD and HD groups, respectively. The average weight, body mass index, and body composition was similar between groups and did not change with EAAS.

Intrahepatic Lipid. IHL was elevated at baseline in both groups and decreased by $23 \%$ in the HD group with EAAS, presumably due to increased protein synthesis [24] (Figure 3). The significant reduction in IHL represented approximately half of the reduction needed to return IHL to normal levels $[25,26]$ but our observation is limited by the relatively small sample and the lack of a control group.

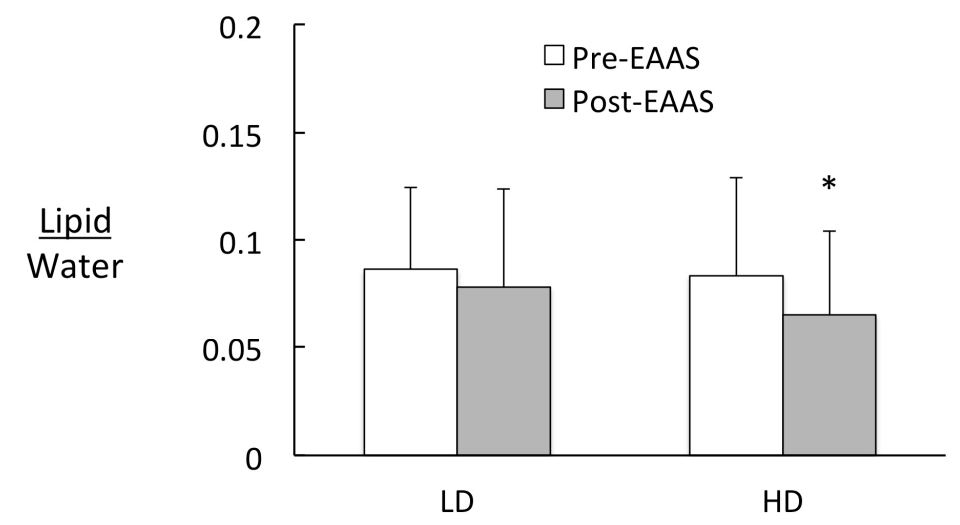

Figure 3. Intrahepatic lipid in low dose (LD) and high dose (HD) pre- and post-essential amino acid supplement (EAAS). ${ }^{*}$ Represents a significant difference between pre- and post-EAAS $(p=0.02)$.

Blood parameters. Total cholesterol, LDL-cholesterol, VLDL-cholesterol, HDL-cholesterol, and triglycerides were all within normal limits and did not differ between groups and did not change with EAAS (Table 2). Except for blood Peth, all other blood parameters were also within normal limits and were not altered by EAAS, indicating the lack of any undesirable effects of EAAS on lipid, liver or metabolic function (Table 2). It is indeed possible that variations in some of these 
parameters may have precluded an opportunity to reject the null hypothesis and this warrants further examination of baseline dietary intake and/or physical activity levels. Blood Peth levels were elevated but not different between groups and were not altered from pre- to post-supplementation in either group. Blood Peth levels above $400 \mathrm{ng} / \mathrm{dl}$ confirmed alcohol misuse in all participants (Table 2) [27].

Table 2. Clinical characteristics.

\begin{tabular}{cccccc}
\hline & Pre-EAAS & Post-EAAS & Pre-EAAS & Post-EAAS & NORMAL \\
& LD & LD & HD & HD & RANGE \\
\hline Sex (F/M) & $4 / 4$ & $4 / 4$ & $2 / 7$ & $2 / 7$ & - \\
Weight (kg) & $81 \pm 11$ & $81 \pm 10$ & $74 \pm 11$ & $74 \pm 12$ & - \\
Body Mass Index (kg/m²) & $26 \pm 3$ & $26 \pm 1$ & $25 \pm 4$ & $25 \pm 4$ & $18.5-25.9$ \\
Fat Mass (kg) & $20 \pm 7$ & $19 \pm 7$ & $19 \pm 7$ & $19 \pm 7$ & - \\
Lean Tissue Mass (kg) & $57 \pm 11$ & $58 \pm 11$ & $51 \pm 8$ & $51 \pm 8$ & - \\
Total Cholesterol (mg/dL) & $187 \pm 26$ & $176 \pm 21$ & $184 \pm 32$ & $186 \pm 35$ & $100-199$ \\
LDL-cholesterol (mg/dL) & $100 \pm 22$ & $87 \pm 21$ & $105 \pm 17$ & $103 \pm 21$ & $0-99$ \\
VLDL-cholesterol (mg/dL) & $23 \pm 13$ & $35 \pm 24$ & $22 \pm 22$ & $23 \pm 20$ & $5-40$ \\
HDL-cholesterol (mg/dL) & $57 \pm 13$ & $55 \pm 14$ & $58 \pm 12$ & $60 \pm 12$ & $>39$ \\
Triglycerides (mg/dL) & $152 \pm 113$ & $175 \pm 115$ & $107 \pm 13$ & $117 \pm 98$ & $0-149$ \\
Albumin (g/dL) & $4.5 \pm 0.4$ & $4.4 \pm 0.3$ & $4.5 \pm 0.2$ & $4.6 \pm 0.1$ & $3.5-5.5$ \\
ALT (IU/L) & $25 \pm 11$ & $18 \pm 7$ & $20 \pm 10$ & $18 \pm 9$ & $0-44$ \\
AST (IU/L) & $23 \pm 7$ & $19 \pm 5$ & $22 \pm 6$ & $29 \pm 21$ & $0-40$ \\
Bilirubin-total (mg/dL) & $0.5 \pm 0.3$ & $0.5 \pm 0.3$ & $0.7 \pm 0.6$ & $0.6 \pm 0.2$ & $0.0-1.2$ \\
Bilirubin-direct (mg/dL) & $0.1 \pm 0.1$ & $0.1 \pm 0.1$ & $0.2 \pm 0.1$ & $0.2 \pm 0.0$ & $0.0-0.4$ \\
Protein-total (g/dL) & $7.1 \pm 0.4$ & $6.7 \pm 0.4$ & $7.0 \pm 0.4$ & $6.8 \pm 0.4$ & $6.0-8.5$ \\
BUN (mg/dL) & $14 \pm 4$ & $14 \pm 4$ & $16 \pm 5$ & $16 \pm 4$ & $6-24$ \\
Calcium (mg/dL) & $9.4 \pm 0.2$ & $9.5 \pm 0.2$ & $9.5 \pm 0.3$ & $9.4 \pm 0.3$ & $8.7-10.2$ \\
Carbon Dioxide (mmol/L) & $24 \pm 1$ & $24 \pm 1$ & $24 \pm 2$ & $25 \pm 1$ & $20-29$ \\
Chloride (mmol/L) & $102 \pm 1$ & $100 \pm 1$ & $101 \pm 2$ & $101 \pm 2$ & $96-106$ \\
Creatinine (mg/dL) & $0.9 \pm 0.1$ & $0.9 \pm 0.1$ & $0.9 \pm 0.2$ & $0.9 \pm 0.1$ & $0.76-1.27$ \\
Glucose (mg/dL) & $90 \pm 7$ & $90 \pm 5$ & $85 \pm 5$ & $86 \pm 7$ & $65-99$ \\
Potassium (mmol/L) & $4.5 \pm 0.4$ & $4.3 \pm 0.2$ & $4.3 \pm 0.2$ & $4.4 \pm 0.2$ & $3.5-5.2$ \\
Sodium (mmol/L) & $141 \pm 1$ & $140 \pm 2$ & $141 \pm 1$ & $142 \pm 1$ & $134-144$ \\
Peth (ng/mL) & $407 \pm 141$ & $429 \pm 196$ & $429 \pm 196$ & $422 \pm 224$ & $<20$ \\
\hline
\end{tabular}

\section{Discussion}

The primary focus of this exploratory pilot investigation was to determine whether EAAS BID would decrease IHL in individuals with mild to moderate AUD. We have now demonstrated that $13 \mathrm{~g}$ of EAAS provided BID significantly reduced IHL without manipulation of dietary intake, change in habitual alcohol consumption, or any form of behavioral modification. On the other hand, $8 \mathrm{~g}$ of EAAS BID did not influence IHL. Given the overall normal ranges for blood parameters except for Peth, it was not surprising that there were no changes in circulating lipid, liver, or metabolic blood parameters in either group. Future studies in a larger cohort with a longer intervention paradigm are now warranted to evaluate whether these efficacious alterations persist and whether lower doses of EAAS could IHL.

Several studies have posited the beneficial influence of essential amino acids on the mitigation of hepatic steatosis [28-31]. To date, this work has focused on nonalcoholic hepatic steatosis, which also describes an excessive accumulation of IHL similar to alcoholic hepatic steatosis [32]. Recommendations suggest that a diet containing foods with more favorable glycemic indexes and energy values coupled with reductions in saturated fat intake should be combined with increased exercise and weight reduction to lower IHL in those with non-alcoholic hepatic steatosis [33]. Unfortunately, adherence to behavioral modification and/or lifestyle intervention has proven extremely difficult [34] for many individuals with hepatic steatosis; regardless of the underlying pathology.

The mechanisms responsible for EAAS-mediated improvements in IHL in the current study may be linked to their influence on mitochondrial biogenesis [35] and/or the complex modulation 
of AMPK $\alpha$, mTOR, sirtuin-1, and PPAR- $\gamma$, all of which regulate pathways of fatty acid kinetics [31]. The provision of EAAS has also been demonstrated to reduce insulin resistance, a common factor implicated in the excessive deposition of lipids in the liver [36]. In the current study, subjects had normal blood glucose concentrations and thus mitigation of insulin resistance was unlikely to have been a significant factor in reducing IHL. Whereas a nonspecific increase in overall dietary protein intake might introduce unnecessary nonessential amino acids linked to excess ammonia and urea production [37], provision of the higher dose of EAAS BID may improve IHL through augmentation of mitochondrial volume and turnover [38].

Suppression of mTORC1 via alcohol intake presents a completely different physiological circumstance [39] than the association between BCAAs and increased mTORC1 in obesity [40]. Given that mTORC1 is vitally important in the stimulation of mitochondrial biogenesis and the corresponding increment in oxidative metabolism needed to support anabolism of metabolic machinery [41], it is not surprising that the provision of EAAS provided beneficial alterations in IHL. While the risks for the development of metabolic syndrome in individuals with AUD are two-fold higher than the rest of the population [42], this is likely due to interactions between dietary intake, lack of physical activity, and alcohol intake [43]. The serum lipids in our participants were within normal limits or borderline high. In the absence of weight loss, it was relatively unlikely for cholesterol or triglycerides to decrease in non-obese individuals.

Regardless of the lack of therapeutic benefit of EAAS on serum lipids that were not elevated by established clinical standards, the beneficial reduction in IHL was significant. Other studies have demonstrated similar benefits in individuals at risk for metabolic diseases [31,44], but this is the first study to our knowledge that has established a link between EAAS and the reduction of IHL in individuals with AUD. It is our assertion that EAAS may have likely improved cytosolic concentrations of amino acids in the liver, which positively altered mitochondrial protein synthesis as previously demonstrated in pre-clinical studies [20]. Combined with the impact of EAAS on transcription via their influence on mTOR [45], these molecular avenues may have allowed EAAS to exert its beneficial influence on mitochondrial biogenesis. While these possibilities are intriguing, our study did not specifically evaluate EAAS-induced alterations in mitochondrial function but rather provide an impetus for future studies that could define the precise mechanisms.

We recognize that the lack of strict dietary control and/or management of physical activity patterns represent the limitations of our study design as both factors may affect IHL [46,47]. Nonetheless, the BMI of our participants indicated that obesity was unlikely to be a contributing factor in the accumulation of excess IHL and the exemption of individuals with diabetes eliminated the influence of that particular disease process on liver metabolism. Instead, we chose to focus on the efficacy of a simple nutritional therapy (i.e., EAAS) on IHL in the context of alcohol misuse (as supported by elevated and stable Peth levels) [48]. This strategy was consistent with our intention to minimize the complexity of the intervention, maximize EAAS compliance, and improve the potential for practical applications based on solid clinical evidence.

Finally, why provide a supplement that could somewhat offset the deleterious influence of alcohol on liver metabolism? The answer to this important question lies in the fact that less than $7 \%$ of individuals with AUD will actually seek professional treatment [49], even though early mitigation of steatosis may delay the progression of alcoholic liver disease [50]. Despite the modest number of individuals who actually seek treatment, progress in early treatment has been made, including reduced stigma for behavioral services, classification of excess alcohol use as a disorder, as well as providing confidential access to national substance abuse and distress helplines. Educational initiatives have also been implemented to improve the recognition of excess alcohol use [2]. As indicated by aminotransferase levels within normal limits in our own participants, hepatic steatosis will likely exist prior to the ability to detect liver damage via blood sampling/evaluation [51,52]. Given that treatment for this disorder is complex [53], therapeutic options should use a multifaceted approach to decrease the pernicious influence of alcohol-induced hepatic steatosis on health outcomes. Otherwise, the complex 
etiology of alcohol-related liver disease; including poor nutritional status [54], impairments in fatty acid oxidation [52], and perturbations in the NADH: NAD+ ratio will continue to worsen the condition of the liver [55].

\section{Conclusions}

Our study has some important limitations that include small sample size and the lack of baseline dietary information. Despite these factors, we have demonstrated that EAAS reduces IHL in individuals with AUD despite continual and consistent alcohol consumption. Future clinical studies should be directed toward a larger cohort with variable levels of dyslipidemia and longer EAAS interventions.

Author Contributions: Conceptualization, R.R.W. and R.H.C.; methodology, M.S.C., R.R.W., and R.H.C.; formal analysis, M.S.C., K.R.L., J.K., C.J.M., R.D., B.R.N., and R.H.C.; investigation, M.S.C., K.R.L., J.K., C.J.M., B.R.N., and R.H.C; data curation, M.S.C., K.R.L., J.K., C.J.M., B.R.N., and R.H.C, writing-original draft preparation, M.S.C. and R.H.C; writing-review and editing, M.S.C., C.J.M., R.R.W., and R.H.C; project administration, M.S.C., R.D., and R.H.C.; funding acquisition; R.R.W. and R.H.C. All authors have read and agreed to the published version of the manuscript.

Funding: Research reported in this publication was supported by Essential Blends, LLC. Research support was also provided by an Institutional Development Award (IDeA) under grant number P20GM103395 and the Biomedical Learning and Student Training Program (UL1GM118991, TL4GM118992, or RL5GM118990) and Award Number P20GM130443 through the National Institute Of General Medical Sciences of the National Institutes of Health. The content is solely the responsibility of the authors and does not necessarily represent the official views of the National Institutes of Health. The University of Alaska Fairbanks, University of Arkansas for Medical Sciences, and James Madison University are affirmative action/equal employment opportunity employers and educational institutions.

Acknowledgments: We would like to express our sincere appreciation to our participants from the Fairbanks area that volunteered their time and effort for this study. We also thank Forrest Clark, Michelle Johannsen, and Ken Shin for the technical assistance in this study, and Andrew Saxon at the University of Washington for his clinical insight and consultation.

Conflicts of Interest: Coker and Wolfe are Managing Partners and Co-Owners of Essential Blends, LLC that have received funding through the Small Business Innovations in Research from the National Institutes of Health to develop clinical nutrition products. We declare that the results of the study are presented clearly, honestly, and without fabrication, falsification, or inappropriate data manipulation.

\section{References}

1. Afshar, M.; Burnham, E.L.; Joyce, C.; Clark, B.J.; Yong, M.; Gaydos, J.; Cooper, R.S.; Smith, G.S.; Kovacs, E.J.; Lowery, E.M. Cut-point levels of phosphatidylethanol to identify alcohol misuse in a mixed cohort including critically Ill patients. Alcohol. Clin. Exp. Res. 2017, 41, 1745-1753. [CrossRef] [PubMed]

2. National Institute of Alcohol Abuse and Alcoholism. Alcohol Facts and Statistics. NIH Publication: Bethesda, MD, USA. Available online: https:/www.niaaa.nih.gov/publications/brochures-and-fact-sheets/alcoholfacts-and-statistics (accessed on 5 December 2019).

3. Alcoholism. Alcohol Use Disorder: A Comparison between DSM-IV and DSM-V; NIH Publication: Bethesda, MD, USA, 2013. Available online: https://www.niaaa.nih.gov/publications/brochures-and-fact-sheets/alcoholuse-disorder-comparison-between-dsm (accessed on 10 December 2019).

4. Baldwin, L.-M.; Hassell, L.; Laukes, C.; Doyle, M.; Reedy, A.; Mollis, B.; Albritton, S.; Ciemins, E.; Coker, R.; Brant, J.; et al. The Northwest Participant and Clinical Interactions Network: Increasing opportunities for patients to participate in research across the Northwestern United States. J. Clin. Transl. Sci. 2017, 1, 94-100. [CrossRef] [PubMed]

5. Bays, H.E. “Sick fat," metabolic disease, and atherosclerosis. Am. J. Med. 2009, 122, S26-S37. [CrossRef] [PubMed]

6. Begriche, K.; Massart, J.; Robin, M.A.; Borgne-Sanchez, A.; Fromenty, B. Drug-induced toxicity on mitochondria and lipid metabolism: Mechanistic diversity and deleterious consequences for the liver. J. Hepatol. 2011, 54, 773-794. [CrossRef] [PubMed]

7. Børsheim, E.; Bui, Q.-U.T.; Tissier, S.; Cree, M.G.; Rønsen, O.; Morio, B.; Ferrando, A.A.; Kobayashi, H.; Wolfe, R.R. Amino acid supplementation decreases plasma and liver triacylglycerols in elderly. Nutrition 2009, 25, 281-288. [CrossRef] [PubMed] 
8. Børsheim, E.; Bui, Q.-U.T.; Tissier, S.; Kobayashi, H.; Ferrando, A.A.; Wolfe, R.R. Effect of amino acid supplementation on muscle mass, strength and physical function in elderly. Clin. Nutr. 2008, 27, 189-195. [CrossRef]

9. Burgess, E.; Hassmén, P.; Welvaert, M.; Pumpa, K.L. Behavioural treatment strategies improve adherence to lifestyle intervention programmes in adults with obesity: A systematic review and meta-analysis. Clin. Obes. 2017, 7, 105-114. [CrossRef]

10. Cheng, Y.; Zhang, K.; Chen, Y.; Li, Y.; Li, Y.; Fu, K.; Feng, R. Associations between dietary nutrient intakes and hepatic lipid contents in NAFLD patients quantified by 1 H-MRS and dual-echo MRI. Nutrients 2016, 8, 527. [CrossRef]

11. Coker, R.H.; Miller, S.; Schutzler, S.; Deutz, N.E.; Wolfe, R.R. Whey protein and essential amino acids promote the reduction of adipose tissue and increased muscle protein synthesis during caloric restriction-induced weight loss in elderly, obese individuals. Nutr. J. 2012, 11, 105. [CrossRef]

12. Coker, R.H.; Coker, M.S.; Bartlett, L.; Murphy, C.J.; Priebe, K.; Shriver, T.C.; Schoeller, D.A.; Ruby, B.C. The energy requirements and metabolic benefits of wilderness hunting in Alaska. Physiol. Rep. 2018, 6, e13925. [CrossRef]

13. Coker, R.H.; Shin, K.; Scholten, K.; Johannsen, M.; Tsigonis, J.; Kim, I.Y.; Schutzler, S.E.; Wolfe, R.R. Essential amino acid-enriched meal replacement promotes superior net protein balance in older, overweight adults. Clin. Nutr. 2019, 38, 2821-2826. [CrossRef]

14. Coker, R.H.; Murphy, C.J.; Johannsen, M.; Galvin, G.; Ruby, B.C. Wildland firefighting: Adverse influence on indices of metabolic and cardiovascular health. J. Occup. Environ. Med. 2019, 61, e91-e94. [CrossRef] [PubMed]

15. Day, C.P.; James, O.F.W. Hepatic steatosis: Innocent bystander or guilty party? Hepatology 1998, 27, $1463-1466$. [CrossRef] [PubMed]

16. Diehl, A.M.E.; Mitchell, M.C.; Herlong, H.F.; Potter, J.J.; Wacker, L.; Mezey, E. Changes in plasma amino acids during sobriety in alcoholic patients with and without liver disease. Am. J. Clin. Nutr. 1986, 44, 453-460. [CrossRef]

17. Ding, W.; Li, M.; Chen, X.; Ni, H.; Lin, C.; Gao, W.; Lu, B.; Stolz, D.B.; Clemens, D.L.; Yin, X. Autophagy reduces acute ethanol-induced hepatotoxicity and steatosis in mice. Gastroenterology 2010, 139, 1740-1752. [CrossRef]

18. Foerster, M.; Marques-Vidal, P.; Gmel, G.; Daeppen, J.-B.; Cornuz, J.; Hayoz, D.; Pecoud, A.; Mooser, V.; Waeber, G.; Vollenweider, P.; et al. Alcohol drinking and cardiovascular risk in a population with high mean alcohol consumption. Am. J. Cardiol. 2009, 103, 361-368. [CrossRef]

19. Griffin, J.W.D.; Bradshaw, P.C. Effects of a high protein diet and liver disease in an in silico model of human ammonia metabolism. Theor. Biol. Med. Model. 2019, 16, 11-14. [CrossRef]

20. Hamad, E.M.; Taha, S.H.; Abou Dawood, A.G.I.; Sitohy, M.Z.; Abdel-Hamid, M. Protective effect of whey proteins against nonalcoholic fatty liver in rats. Lipids Health Dis. 2011, 10, 57. [CrossRef] [PubMed]

21. Hoek, J.B.; Cahill, A.; Pastorino, J.G. Alcohol and mitochondria: A dysfunctional relationship. Gastroenterology 2002, 122, 2049-2063. [CrossRef] [PubMed]

22. Holecek, M. Three targets of branched-chain amino acid supplementation in the treatment of liver disease. Nutrition 2010, 26, 482-490. [CrossRef] [PubMed]

23. Jeznach-Steinhagen, A.; Ostrowska, J.; Czerwonogrodzka-Senczyna, A.; Boniecka, I.; Gronostajska, W. Dietetary recommendation for non-alcoholic fatty liver disease. Pol. Merkur. Lek. Organ Pol. Tow. Lek. 2017, 9, 18-23.

24. Katsanos, C.S.; Kobayashi, H.; Sheffield-Moore, M.; Aarsland, A.; Wolfe, R.R. A high proportion of leucine is required for optimal stimulation of the rate of muscle protein synthesis by essential amino acids in the elderly. Am. J. Physiol. Endocrinol. Metab. 2006, 191, E381-E387. [CrossRef] [PubMed]

25. Kranzler, H.R.; Soyka, M. Diagnosis and pharmacotherapy of alcohol use disorder a review. JAMA 2018, 320, 815-824. [CrossRef] [PubMed]

26. Laplante, M.; Sabatini, D.M. mTOR signaling at a glance. J. Cell Sci. 2009, 122, 3589-3594. [CrossRef]

27. Larson-Meyer, D.E.; Heilbronn, L.K.; Redman, L.M.; Newcomer, B.R.; Frisard, M.I.; Anton, S.; Smith, S.R.; Alfonso, A.; Ravussin, E. Effect of calorie restriction with or without exercise on insulin sensitivity, $\beta$-cell function, fat cell size, and ectopic lipid in overweight subjects. Diabetes Care 2006, 29, 1337-1344. [CrossRef]

28. Lewis, M.J. Alcohol and nutrient intake: Mechanisms of reinforcement and dependence. Physiol. Behav. 2011, 104, 138-142. [CrossRef] 
29. Liangpunsakul, S.; Qi, R.; Crabb, D.W.; Witzmann, F. Relationship between alcohol drinking and aspartate aminotransferase: Alanine aminotransferase (AST:ALT) ratio, mean corpuscular volume (MCV), gamma-glutamyl transpeptidase (GGT), and apolipoprotein A1 and B in the U.S. population. J. Stud. Alcohol Drugs. 2010, 71, 249-252. [CrossRef]

30. Lieber, C.S. Relationships between nutrition, alcohol use, and liver disease. Alcohol Res. Health 2003, 27, 220-231.

31. Matsubara, F.; Nagai, Y.; Tsukiyama, H.; Shimizu, H.; Yamanouchi, E.; Iwamoto, T.; Sada, Y.; Kato, H.; Ohta, A.; Tanaka, Y. Proposed cut-off value of the intrahepatic lipid content for metabolically normal persons assessed by proton magnetic resonance spectroscopy in a Japanese population. Diabetes Res. Clin. Pract. 2016, 119, 75-82. [CrossRef]

32. McCarty, M.F. Nutraceutical strategies for ameliorating the toxic effects of alcohol. Med. Hypotheses 2013, 80, 456-462. [CrossRef]

33. Melser, S.; Lavie, J.; Bénard, G. Mitochondrial degradation and energy metabolism. Biochim. Biophys. Acta 2015, 1853, 2812-2821. [CrossRef] [PubMed]

34. Mendenhall, C.L.; Moritz, T.E.; Roselle, G.A.; Morgan, T.R.; Nemchausky, B.A.; Tamburro, C.H.; Schiff, E.R.; McClain, C.J.; Marsano, L.S.; Allen, J.I.; et al. A study of oral nutritional support with oxandrolone in malnourished patients with alcoholic hepatitis: Results of a department of veterans affairs cooperative study. Hepatology 1993, 17, 564-576. [CrossRef] [PubMed]

35. Mendenhall, C.; Roselle, G.A.; Gartside, P.; Moritz, T. Relationship of protein calorie malnutrition to alcoholic liver disease: A reexamination of data from two veterans administration cooperative studies. Alcohol. Clin. Exp. Res. 1995, 19, 635-641. [CrossRef] [PubMed]

36. Ontko, J.A. Effects of ethanol on the metabolism of free fatty acids in isolated liver cells. J. Lipid Res. 1973, 14, 78-86. [PubMed]

37. Plauth, M.; Bernal, W.; Dasarathy, S.; Merli, M.; Plank, L.D.; Schütz, T.; Bischoff, S.C. ESPEN guideline on clinical nutrition in liver disease. Clin. Nutr. 2019, 38, 485-521. [CrossRef] [PubMed]

38. Reddy, J.K.; Rao, M.S. Lipid metabolism and liver inflammation. II. Fatty liver disease and fatty acid oxidation. Am. J. Physiol. Gastrointest. Liver Physiol. 2006, 290, G852-G858. [CrossRef]

39. Rehm, J.; Gmel, G.E.; Gmel, G.; Hasan, O.S.M.; Imtiaz, S.; Popova, S.; Probst, C.; Roerecke, M.; Room, R.; Samokhvalov, A.V.; et al. The relationship between different dimensions of alcohol use and the burden of disease-An update. Addiction 2017, 112, 968-1001. [CrossRef]

40. Rinella, M.E. Nonalcoholic fatty liver disease a systematic review. JAMA 2015, 313, 2263-2273. [CrossRef] [PubMed]

41. Ross-Inta, C.; Tsai, C.Y.; Giulivi, C. The mitochondrial pool of free amino acids reflects the composition of mitochondrial DNA-encoded proteins: Indication of a posttranslational quality control for protein synthesis. Biosci. Rep. 2008, 28, 239-249. [CrossRef] [PubMed]

42. Solon-Biet, S.M.; Cogger, V.C.; Pulpitel, T.; Wahl, D.; Clark, X.; Bagley, E.E.; Gregoriou, G.C.; Senior, A.M.; Wang, Q.P.; Brandon, A.E.; et al. Branched-chain amino acids impact health and lifespan indirectly via amino acid balance and appetite control. Nat. Metab. 2019, 1, 532-545. [CrossRef] [PubMed]

43. Tajiri, K.; Shimizu, Y. Branched-chain amino acids in liver diseases. World J. Gastroenterol. 2013, 19, 7620-7629. [CrossRef] [PubMed]

44. Theytaz, F.; Noguchi, Y.; Egli, L.; Campos, V.; Buehler, T.; Hodson, L.; Patterson, B.W.; Nishikata, N.; Mittendorfer, B.; Fielding, B.; et al. Effects of supplementation with essential amino acids on intrahepatic lipid concentrations during fructose overfeeding in humans. Am. J. Clin. Nutr. 2012, 96, 1008-1016. [CrossRef] [PubMed]

45. Thoreen, C.C.; Chantranupong, L.; Keys, H.R.; Wang, T.; Gray, N.S.; Sabatini, D.M. A unifying model for mTORC1-mediated regulation of mRNA translation. Nature 2012, 485, 109-113. [CrossRef] [PubMed]

46. Torruellas, C.; French, S.W.; Medici, V. Diagnosis of alcoholic liver disease. World J. Gastroenterol. 2014, 20, 11684-11699. [CrossRef] [PubMed]

47. Toshikuni, N.; Tsutsumi, M.; Arisawa, T. Clinical differences between alcoholic liver disease and nonalcoholic fatty liver disease. World J. Gastroenterol. 2014, 20, 8393-8406. [CrossRef] [PubMed]

48. Van Herpen, N.A.; Schrauwen-Hinderling, V.B. Lipid accumulation in non-adipose tissue and lipotoxicity. Physiol. Behav. 2008, 94, 231-241. [CrossRef] 
49. Vancampfort, D.; Hallgren, M.; Mugisha, J.; De Hert, M.; Probst, M.; Monsieur, D.; Stubbs, B. The prevalence of metabolic syndrome in alcohol use disorders: A systematic review and meta-analysis. Alcohol Alcohol. 2016, 51, 515-521. [CrossRef]

50. Viel, G.; Boscolo-Berto, R.; Cecchetto, G.; Fais, P.; Nalesso, A.; Ferrara, S.D. Phosphatidylethanol in blood as a marker of chronic alcohol use: A systematic review and meta-analysis. Int. J. Mol. Sci. 2012, 13, 14788-14812. [CrossRef]

51. Wolfe, R.R. The underappreciated role of muscle in health and disease. Am. J. Clin. Nutr. 2006, 84, 475-482. [CrossRef]

52. Wolfe, R.R.; Cifelli, A.M.; Kostas, G.; Kim, I.-Y. Optimizing protein intake in adults: Interpretation and application of the recommended dietary allowance compared with the acceptable macronutrient distribution range. Adv. Nutr. 2017, 8, 266-275. [CrossRef]

53. World Health Organization. The Global Burden of Disease: 2004 Update; World Health Organization: Geneva, Switzerland, 2008; Available online: https:/www.who.int/healthinfo/global_burden_disease/2004_ report_update/en/ (accessed on 5 December 2019). [CrossRef]

54. Baraona, E.; Lieber, C.S. Effect of ethanol on lipid metabolism. J. Lipid. Res. 1979, 20, 289-315. [CrossRef] [PubMed]

55. Zhou, M.; Shao, J.; Wu, C.-Y.; Shu, L.; Dong, W.; Liu, Y.; Chen, M.; Wynn, R.M.; Wang, J.; Wang, J.; et al. Targeting BCAA catabolism to treat obesity-associated insulin resistance. Diabetes 2019, 68, 1730-1746. [CrossRef] [PubMed]

(C) 2020 by the authors. Licensee MDPI, Basel, Switzerland. This article is an open access article distributed under the terms and conditions of the Creative Commons Attribution (CC BY) license (http://creativecommons.org/licenses/by/4.0/). 